\title{
Awareness of Patients toward Dental Implants as an Alternative Treatment to Replace Missing Teeth in Kinshasa, D. R. Congo
}

\author{
Em Kalala-Kazadi1 ${ }^{*}$, Patrick Disidi-Yakini' ${ }^{1}$, Fidèle Nyimi-Bushaba ${ }^{2,3}$, \\ Edize Ekofo-Ingaya ${ }^{1}$, Augustin Mantshumba-Milolo ${ }^{4}$ \\ ${ }^{1}$ Unit of Periodontology, Department of Dental Medicine, Faculty of Medicine, University of Kinshasa, Kinshasa, Congo \\ ${ }^{2}$ Oral and Maxillo-Facial Surgery, University of Kinshasa and, Kinshasa, Congo \\ ${ }^{3}$ Wuhan University, Wuhan, China \\ ${ }^{4}$ Prosthesis and Orthodontic Service, Department of Dental Medicine, Faculty of Medicine, University of Kinshasa, Kinshasa, Congo \\ Email: *kalalaem@gmail.com, *em.kalala@unikin.ac.cd
}

How to cite this paper: Kalala-Kazadi, E., Disidi-Yakini, P., Nyimi-Bushaba, F., Ekofo-Ingaya, E. and Mantshumba-Milolo, A. (2018) Awareness of Patients toward Dental Implants as an Alternative Treatment to Replace Missing Teeth in Kinshasa, D. R. Congo. Open Journal of Stomatology, 8, 345-353.

https://doi.org/10.4236/ojst.2018.812033

Received: September 20, 2018

Accepted: December 16, 2018

Published: December 19, 2018

Copyright (c) 2018 by authors and Scientific Research Publishing Inc. This work is licensed under the Creative Commons Attribution International License (CC BY 4.0).

http://creativecommons.org/licenses/by/4.0/

\section{(c) (i) Open Access}

\begin{abstract}
Background: Dental implant is an artificial root inserted in the jawbone, which restores a lost tooth so that it looks, feels, and is fit like a natural tooth. It is considered to be the best treatment option for single or multiple missing teeth. The aim of this study was to assess the awareness of patients about dental implants as an alternative treatment in Congolese patients. Materials and Methods: A cross-sectional study was conducted in two institutions namely, CBCO Bandal and Ngaliema Clinic, from August to December 2017. A total of 450 respondents have participated in the survey. A printed questionnaire comprised of 20 questions in order to evaluate patients dental awareness was used. Gender, level of education, awareness of dental implant and dental implants therapy, sources of information and the expectation about the sources of information were assessed. The collected data were entered in Microsoft Excel 2010 and analyzed by SPSS (IBM SPSS 20.0, Chicago, IL, USA) software. Results: Out of 450 participants, $14.4 \%$ were aware of dental implants. The main disadvantage of dental implant was the high cost. When asked about the anchorage, $86 \%$ didn't know where the dental implant was anchored. Ninety-two percent didn't know for how long an implant last, $6 \%$ thought that dental implant last for a lifetime. When patients were asked about the sources of information, the dentist (5\%) and media (5.5\%) were the main sources of information. The majority of patients (88.4\%) would like to get information about dental implants from their dentist. Conclusion: Dentists should be more involved in the promotion of information about dental implants as a treatment modality to replace missing teeth.
\end{abstract}




\section{Keywords}

Awareness, Dental Implant, Treatment Modality, Oral Rehabilitation

\section{Introduction}

The well-being and quality of life are often affected by the common oral changes and conditions of the individuals. The loss of natural teeth is a health problem that is associated with functional, cosmetic, psychological morbidities and disabilities in daily living activities such as impaired eating and speaking, or social embarrassment. Various attempts have been made to replace the lost dentition with artificial teeth (prostheses) that resemble the natural teeth in function and appearance. Fortunately, restoration of missing teeth with dental implants offers far-reaching solution to the problems [1] [2].

A dental implant is an artificial root inserted in the jawbone, which restores a lost tooth so that it looks, feels, and is fit like a natural tooth [3] [4].

The dental implant treatment is considered to be the best treatment option for single or multiple missing teeth. It is estimated that one million implants are placed in the world yearly [5].

Due to the high success rates and predictability of dental implants, their prevalence in the oral rehabilitation is increasing year by year [6] [7]. In addition implants offer alternative treatment options to fully or partially edentulous patients. A majority of patients treated with implant supported prosthesis have reported improvement in their quality of life, assurance, self-confidence including psychological benefits and moreover conservation of the tooth structure adjacent to the teeth to be replaced [8] [9].

Little information is available to patients regarding dental implant and its success. This problem is more encountered in developing nations where there is a lack of education and awareness among people about dental implants as a treatment modality. Therefore, complete information on implant treatment must be provided to guide the patient in the choice of the most appropriate option [10].

To the best of our knowledge, there is no existing literature regarding the awareness of patients about dental implants in D.R. Congo.

Therefore, the aim of this study was to assess the awareness about dental implants as an alternative treatment among Congolese patients.

\section{Methodology}

\section{- Selection of the study population and questionnaire}

A cross-sectional study was conducted in two institutions namely, CBCO Bandal and Ngaliema Clinic, from August to December 2017. A convenient sample size of 450 respondents agreed to participate to the survey. Their age varied between 18 to 92 years old. The mean age was $35.43 \pm 12.94$ years. They were se- 
lected during their regular visit in the dental services of the two institutions above cited.

To be part of this study, the patient has to accept voluntarily to participate and to be aged 18 years old at least.

The study was approved by the local ethics committee of the University of Kinshasa.

A printed questionnaire comprised of 20 questions in order to evaluate patient dental awareness was given to them. Questionnaire was prepared in French and explained in Lingala (local language) to all participants.

All the respondents were informed about the aim and objectives of the study. Questions used in the survey form included self-explanatory questions which were adapted from a previous study conducted by Tomruk et al. [11].

\section{- Statistical analysis}

The collected data were entered in Microsoft Excel 2010 and analyzed by Statistical Package for Social Sciences (SPSS 20.0, Chicago, IL, USA) software.

\section{Results}

The age of the majority of patients varied between 30 to 50 years old. The majority of them (62.2\%) had a high education level (university and above). The female participants represented $63.6 \%$ whereas the male, $36.4 \%$ (Table 1 ).

Out of 450 patients interviewed in this study, no one had undergone an implant therapy whereas $6.7 \%$ were denture carriers (Table 2).

Regarding the alternatives for replacing teeth, $41.5 \%$ of patients interviewed were aware of partial removable denture; $28.4 \%$ were aware of fixed partial denture whereas only $14.4 \%$ were aware of dental implant as an alternative to replace missing teeth (Table 3 ).

Regarding the assessment of the information level of dental implants, 1.6\% reported that they were very well informed, $3.1 \%$ were well informed and $31.1 \%$ were poorly informed subjectively (Table 3 ).

Seventy one percent didn't know the advantages of non-removable denture vs removable denture, 5.5\% reported that it was "less annoying in the mouth", 17\% said "more esthetic", 5.5\% thought "not like a foreign body", 1\% reported "feel like natural teeth". The high cost was the main disadvantage of dental implant (23\%) (Table 4).

Regarding the anchor of dental implants, $8 \%$ reported that it was in the jaw bone, $6 \%$ answered that it was in the gingiva.

When asked about the lifelong of implants, $0.4 \%$ answered $>5$ years, $0.2 \%$ said $>10$ year, $1 \%$ reported $>20$ years and $6 \%$ answered for lifetime (Table 5).

When the patients were asked about the information sources of dental implants, results reported, dentist (5\%), friends (2.6\%), media (5.5\%), medical doctor (0.7\%) (Table 6).

About the expectation of informations on dental implants, $88.4 \%$ wished to get information of dental implant near the dentist, friends (1.6\%), media (2.4\%), 
medical doctor (6.9\%) and other (0.31) (Table 7).

Table 1. Sociodemographic profile of respondents.

\begin{tabular}{cccc}
\hline & & $\mathrm{n}$ & $\%$ \\
\hline \multirow{2}{*}{ Age } & $<30$ & 182 & 40.4 \\
& $30-50$ & 199 & 44.2 \\
& $51-70$ & 65 & 14.4 \\
Gender & $71+$ & 4 & 0.9 \\
& Male & 174 & 36.4 \\
Education level & Female & 276 & 63.6 \\
& Uneducated & 1 & 0.22 \\
& Primary school & 14 & 3.1 \\
& High school & 155 & 34.1 \\
& University and above & 280 & 62.2 \\
\hline
\end{tabular}

Table 2. Questions on knowledge and dental situation.

\begin{tabular}{cccc}
\hline & & $\mathrm{n}$ & $\%$ \\
\hline Had implant therapy? & Yes & 0 & 0 \\
& No & 450 & 100 \\
Carrying dental prostheses? & Yes & 30 & 6.7 \\
& No & 420 & 93.3 \\
\hline
\end{tabular}

Table 3. Questions on alternative teeth replacement.

\begin{tabular}{cccc}
\hline & & $\mathrm{n}$ & $\%$ \\
\hline Alternatives for replacing teeth & Implant supporting reconstruction & 65 & 14.4 \\
& Removable partial denture & 187 & 41.5 \\
& Removable complete & 6 & 1.3 \\
& Fixed partial denture & 128 & 28.4 \\
& Not at all & 64 & 14.2 \\
How well informed do you feel & Very well & & \\
subjectively about implants? & Well & 7 & 1.6 \\
& Moderately well & 14 & 3.1 \\
& Poorly & 4 & 0.9 \\
& Not at all & 140 & 31.1 \\
& & 285 & 63.3 \\
How well informed do you feel & Very well & 69 & 15.3 \\
subjectively about alternatives & Well & 111 & 24.7 \\
for replacing teeth? & Moderately well & 17 & 3.8 \\
& Poorly & 218 & 48.4 \\
& Not at all & 35 & 7.8 \\
\hline
\end{tabular}


Table 4. Questions on advantages and disadvantages of different dentures.

\begin{tabular}{cccc}
\hline & & $\mathrm{n}$ & $\%$ \\
\hline & Less annoying in the mouth & 25 & 5.5 \\
What are the advantages of non-removable & Esthetic (nicer) & 77 & 17 \\
vs removable dentures? & Foreign body & 25 & 5.5 \\
& Good as natural teeth & 5 & 1 \\
& I don't know & 318 & 71 \\
What do you think are the disadvantages & High cost & 103 & 23 \\
of implant-supported dentures/bridges? & Need for surgery & 21 & 4.6 \\
& Long treatment time & 8 & 2 \\
& I don't know & 317 & 70.4 \\
\hline
\end{tabular}

Table 5. Questions on anchorage and lifelong of implants.

\begin{tabular}{cccc}
\hline & & $\mathrm{n}$ & $\%$ \\
\hline \multirow{2}{*}{$\begin{array}{c}\text { Where the implants } \\
\text { are anchored }\end{array}$} & Jaw bone & 36 & 8 \\
& Gingiva & 27 & 6 \\
Lifelong of an implant & I don't know & 387 & 86 \\
& $>5$ years & 2 & 0.4 \\
& $>10$ years & 1 & 0.2 \\
& $>20$ years & 4 & 1 \\
& Lifetime & 27 & 6 \\
& I don't know & 416 & 92.4 \\
\hline
\end{tabular}

Table 6. Questions on the sources of information about alternatives for replacement of teeth.

\begin{tabular}{cccc}
\hline & & $\mathrm{n}$ & $\%$ \\
\hline & Dentist & 22 & 5 \\
The sources of information & Friends & 12 & 2.6 \\
About dental implant & Media & 25 & 5.5 \\
& Medical doctor & 3 & 0.7 \\
& Other & 1 & 0.2 \\
& No answer & 387 & 86 \\
The sources of information about & Dentist & 126 & 28 \\
alternatives for replacement of teeth & Friends & 197 & 43.8 \\
& Media & 72 & 16 \\
& Medical doctor & 15 & 3.3 \\
& Other & 14 & 3.1 \\
& No answer & 26 & 5.8 \\
\hline
\end{tabular}

Table 7. Questions on expectations about the source of information.

\begin{tabular}{cccc}
\hline & & $\mathrm{n}$ & $\%$ \\
\hline & Dentist & 398 & 88.4 \\
From where would you like to get & Friends & 7 & 1.6 \\
information about implants & Media & 11 & 2.4 \\
& Medical doctor & 31 & 6.9 \\
\hline
\end{tabular}




\section{Discussion}

The objective of this study was to assess the awareness level of patients about dental implant as an alternative treatment for oral rehabilitation. In the recent decades, dental implant has become a popular treatment option in most developed countries.

This survey revealed that no respondent had undergone implant therapy while $6.7 \%$ of patients were prostheses carrier. These results could be explained in the one hand, by the high cost of oral implant rehabilitation and low income of the population [12], and in the other hand by the lack of implants equipment in most hospitals of Kinshasa city.

The awareness of dental implants as an alternative treatment was low with $14.4 \%$. This level of awareness suggests that most of patients attending dental services are not informed about dental implant as an alternative treatment for oral rehabilitation. This argument is important to be mentioned as the number of participants with high level of education (university and above) was high. Therefore, a great work of information have to be done near them. Another low level of awareness was reported in a survey conducted by Mgbeokwere et al. 2011 [2] in the Nigerian population (9.7\%). However, studies done by Zimmer et al. 1992 [13] in the USA, Berge (2000) [14] in Norway, Suprakash et al. 2013 [1] in India, Kohli et al. 2014 in Malaysia [15] reported higher level of awareness either $77 \%, 70.1 \%, 77 \%$, and $72 \%$ respectively.

Only $1.6 \%$ of patients estimated that they were very well informed about dental implants and $15.3 \%$ very well informed about alternatives for replacing teeth. Therefore, patients should be highlighted about different treatment modalities for replacing missing Teeth.

Seventy one percent of respondents didn't know the advantages of non-removable vs removable dentures. These results suggest that dentists have to be more involved in conveying explicit information to patients about different types of dentures and their eventual advantages and disadvantages.

In this survey, the major disadvantage about dental implants as estimated by the participants was the high cost (23\%). This point of view is similar to that of several authors from different countries, developing as well as non developing [11] [13] [16] [17] [18] [19].

In the present study, $86 \%$ didn't know where implants are anchored; only $8 \%$ stated the jaw bone. This result confirms the lack of knowledge about dental implants among patients mentioned above. In a study conducted by Suwal et al. [20], 24.5\% stated that the jaw bone was the site of anchorage of the dental implant. The majority of respondents (92.4\%) were unaware about the durability of dental implants, $1 \%$ thought the lifelong as $>20$ years, $6 \%$ for lifetime. Therefore, patients should be more informed properly about the implant therapy. Unrealistic estimates and expected implant survival time should be cleared up properly before the treatment to prevent misunderstandings and misinformation [11]. 
Regarding the sources of information about dental implants, two main sources were reported; $5.5 \%$ were informed via media, $5 \%$ by dentists. These results corroborate with the study of Zimmer et al. [13]. However, Bhoomika et al. [10], Kholi et al. [17], Kumar et al. [16], Esfahani et al [21], Deeb et al. [22] reported that the main source was the dentist while Suwal et al. [20], Al-Johany et al. [23] reported relatives and friends.

When asked about the expectation on sources of information, the majority $(88.4 \%)$ of patients wished to get information about dental implants from their dentists. These results are in agreement with the study conducted by Tomruk et al. [11]. Dentists As this survey was performed in a limited group of patients, further surveys are needed to take place in a larger population.

As a main shortcoming, this survey was performed in a limited group of patients not randomly selected; future surveys are needed to take place in large samples of the population selected randomly.

\section{Conclusion}

The present study showed that no respondent had undergone implant therapy, patients awareness towards dental implants as an alternative treatment for replacing missing teeth was low. Media and dentists were the main sources of information regarding dental implants among all patients. The major disadvantage of implant as a treatment option was the high cost. Therefore, awareness of dental implants among people should be improved; dentists should be the first line for carrying realistic information. A need for the equipment of hospitals and education of dentists in this field is paramount.

\section{Conflicts of Interest}

The authors declare no conflicts of interest regarding the publication of this paper.

\section{References}

[1] Suprakash, B., Ahammed, A.R.Y., Thareja, A., Kandaswamy, R., Kumar, N. and Bhondwe, S. (2013) Knowledge and Attitude of Patients toward Dental Implants as an Option for Replacement of Missing Teeth. Journal of Contemporary Dental Practice, 14, 115-118. https://doi.org/10.5005/jp-journals-10024-1282

[2] Mgbeokwere, U., Okoye, L. and Ekwueme, O. (2011) A Survey of the Knowledge of Dental Implants as a Choice in Treatment of Edentulous Jaws among Health Workers in Government Dental Clinics in Enugu. Annals of Medical and Health Sciences Research, 1, 91-96.

[3] Naert, I., Koutsikakis, G., Duyck, J., Quirynen, M., Jacobs, R. and van Steenberghe, D. (2002) Biologic Outcome of Implant Supported Restorations in the Treatment of Partial Edentulism. Part I: A Longitudinal Clinical Evaluation. Clinical Oral Implants Research, 13, 381-389. https://doi.org/10.1034/j.1600-0501.2002.130406.x

[4] Brunski, J.B. (1999) In Vivo Bone Response to Biomechanical Loading to Bone/Dental Implant Interface. Advances in Dental Research, 13, 99-119. https://doi.org/10.1177/08959374990130012301 
[5] Chowdhary, R., Mankani, N. and Chandraker, N.K. (2010) Awareness of Dental Implants as a Treatment Choice in Urban Indian Populations. International Journal of Oral \& Maxillofacial Implants, 25, 305-308.

[6] Tepper, G., Haas, R., Mailath, G., Teller, C., Zechner, W., Watzak, G., et al. (2003) Representative Marketing-Oriented Study on Implants in the Austrian Population. I. Level of Information, Sources of Information and Need for Patient Information. Clinical Oral Implants Research, 14, 621-633. https://doi.org/10.1034/j.1600-0501.2003.00916.x

[7] Muller, F., Wahl, G. and Fuhr, K. (1994) Age-Related Satisfaction with Complete Dentures, Desire for Improvement and Attitudes to Implant Treatment. Gerodontology, 11, 7-12. https://doi.org/10.1111/j.1741-2358.1994.tb00096.x

[8] Pommer, B., Zechner, W., Watzak, G., et al. (2011) Progress and Trends in Patients' Mindset on Dental Implants. I: Level of Information, Sources of Information and Need for Patient Information. Clinical Oral Implants Research, 22, 223-229. https://doi.org/10.1111/j.1600-0501.2010.02035.x

[9] Aglietta, M., Siciliano, V.I., Zwahlen, M., Brägger, U., Pjetursson, B.E., Lang, N.P. and Salvi, G.E. (2009) A Systematic Review of the Survival and Complication Rates of Implant Supported Fixed Dental Prostheses with Cantilever Extensions after an Observation Period of at Least 5 Years. Clinical Oral Implants Research, 20, 441-451. https://doi.org/10.1111/j.1600-0501.2009.01706.x

[10] Bhoomika, K. and Devaraj, C.G. (2015) Awareness of Dental Implants as a Treatment Modality among People Visiting Mahatma Gandhi Dental College \& Hospital, Jaipur. National Journal of Medical Research, 5, 61-63.

[11] Tomruk, C.Ö., Özkurt-Kayahan, Z. and Şençift, K. (2014) Patient's Knowledge and Awareness of Dental Implants in a Turkish Subpopulation. Journal of Advanced Prosthodontics, 6, 133-137. https://doi.org/10.4047/jap.2014.6.2.133

[12] Kalala, E.K., Mantshumba, M.A., Vuystek, P., Vinckier, F., Kumpanya, N.P., Lutula, P.J. and Ntumba, M.K. (2014) Implantologie Dentaire Aux Cliniques Universitaires de Kinshasa. Annales Africaines de Médecine, 7, 73-76.

[13] Zimmer, C.M., Zimmer, W.M., Williams, J. and Liesener, J. (1992) Public Awareness and Acceptance of Dental Implants. International Journal of Oral \& Maxillofacial Implants, 7, 228-232.

[14] Berge, T.I. (2000) Public Awareness, Information Sources and Evaluation of Oral Implant Treatment in Norway. Clinical Oral Implants Research, 11, 401-408. https://doi.org/10.1034/j.1600-0501.2000.011005401.x

[15] Kohli, S., Bhatia, S., Kaur, A. and Rathakrishnan, T. (2014) Public Knowledge and Acceptance of Dental Implant Treatment in Malaysian Population. Journal of Interdisciplinary Dentistry, 4, 76-80. https://doi.org/10.4103/2229-5194.142938

[16] Kumar, S. and Chauhan, A. (2015) Knowledge and Awareness of Dental Implants in India: An Exploratory Study. International Journal of Oral Health and Medical Research, 2, 29-33.

[17] Kola, M.Z., Alasqah, M.N., Alharbi, B., Alonazi, A. and Alhedyan, F.S. (2016) Public Awareness, Information Sources and Evaluation of Oral Implant Treatment in Alkharj Town (Kingdom of Saudi Arabia)-A Survey Based Study. Journal of Advanced Medical and Dental Sciences Research, 4, 114-120.

[18] Hosadurga, R., Shanti, T., Hedge, S., Kashyap, R.S. and Arunkumar, S.M. (2017) Awareness, Knowledge and Attitude of Patients towards Dental Implants-Questionnaire Based Prospective Study. Journal of Indian Society of Periodontology, 21, 315-325. 
[19] Awooda, E.M., Eltayeb, A.S., Hussain, S.A., Dayelnaiem, S.I., Abdelhamied, M.A., Mohamed, L.A., et al. (2014) Knowledge, Attitude and Acceptance of Dental Implants among Patients Attending Khartoum Dental Teaching Hospital. IOSR Journal of Dental and Medical Sciences, 13, 19-23.

[20] Suwal, P., Basnet, B.B., Shrestha, B., Parajuli, P.K. and Singh, R.K. (2016) Knowledge, Attitude, and Awareness Regarding Dental Implants among Patients Visiting a University Hospital and Its Teaching Districts. Journal of Dental Implant, 6, 57-61. https://doi.org/10.4103/jdi.jdi_22_16

[21] Esfahani, O.F. and Moosaali, F. (2016) Awareness and Knowledge of Patients toward Dental Implants as an Option in Replacing Missing Teeth: A Survey in Kerman, Iran. Journal of Periodontology \& Implant Dentistry, 8, 43-48.

[22] Deeb, G., Wheeler, B., Jones, M., Carrico, C., Laskin, D., Golob, J. and Deeb, J.G. (2017) Public and Patient Knowledge about Dental Implants. Journal of Oral and Maxillofacial Surgery, 75, 1387-1391. https://doi.org/10.1016/j.joms.2017.03.024

[23] Al-Johany, S., Al Zoman, H.A., Al Juhaini, M. and Al Refeai, M. (2010) Dental Patients' Awareness and Knowledge in Using Dental Implants as an Option in Replacing Missing Teeth: A Survey in Riyadh, Saudi Arabia. Saudi Dental Journal, 22, 183-188. https://doi.org/10.1016/j.sdentj.2010.07.006 